\title{
La contabilidad municipal en el Canadá
}

\author{
II.-CONTABILIDAd Del Fondo PATRIMonial
}

Como señalábamos en nuestro trabajo anterior, la división fundamental de la contabilidad municipal canadiense viene determinada en función de la clasificación financiera de los gastos e ingresos públicos en ordinarios y extraordinarios, resultando así, como uno de los más importantes compartimentos contables, el llamado “Capital and Loan Funds). (Fondos de bienes fijos y préstamos o $\mathrm{Pa}$ trimonial).

La contabilidad de este Fondo tiene por objeto mostrar la situación patrimonial, activa y pasiva del Municipio, considerándo integrado dicho activo, no sólo por los propiamente llamados «bienes patrimonialesi, sino también por los de dominio público.

A través de sus cuentas'activas refleja, principalmente, el costo o valor estimado original de aquellos bienes (caminos, calles, plazas, paseos, obras públicas, edificios, bienes muebles, etc.) y en su pasivo, los empréstitos y préstamos a largo y aun a corto plazo, que constituyen en su conjunto la llamada "deuda municipal" y son la más importante de las fuentes de ingresos extraordinarios de estas economías.

El cuadro de cuentas del Fondo Patrimonial puede apreciarse en el siguiente modelo de Balance de Situación ("exhibit II") del Manual) :

\section{A C T I V O}

1. Fijo general (terrenos, edificios, planta y equipo, calles, alcantariliado, etc.).-Detalle en el estado complementario número uno. 
2. Obras en curso.

3. Débitos de Escuelas, por empréstitos.

31.-Elementales.

32.- Secundarios.

33.-Técnicas y Vocacionales.

34.-..............

4. Débitos de Empresas y Servicios municipalizados por empréstitos.

4.1.- Servicio Municipal de Aguas.

42.-Idem íd. de Electricidad.

43.-Idem íd. de Gas.

44.-Empresa Municipal de Tranvías.

45.-Idem id. de Autobuses.

46.- Servicio Municipal de Teléfonos.

47.-Idem íd. de Calefacción.

48.- "Ferries".

49.-Otros Servicios Municipales (especificar) :

491.--Aeropuerto.

492.-...........

50.- Viviendas.

51.-Comentarios.

52

5. Débitos de otros Municipios por empréstitos (estado complementario número $1(a)$.

6. Fondo de amortización de obligaciones.

7. Tesorería.

8. Cuentas deudoras.

81.-Diversas.

82.-Débitos de otras Entidades locales (excluídos los procedentes de empréstitos).

83.-Débitos de la provincia.

9. Débitos de otros fondos municipales (por otros conceptos que emisión de empréstitos).

10. Otro activo real.

$101 . . . . . . . . . . . . . . .$.

102. $-\ldots \ldots \ldots \ldots \ldots$ 
11. Prima emisión obligaciones (pendiente de amortización).

12. Déficits y gastos extraordinarios capitalizados.

121.-Auxilios paro obrero.

122.-Déficits de presupuestos ordinarios capitalizados.

123. - Gastos extraordinarios que no sean de primer establecimiento.

$$
\text { P A S I vo }
$$

1. Empréstitos municipales (Títulos en circulación.-Estado complementario número 2).

11.-Generales :

111.-Déficits capitalizados.

112.-Auxilios paro obrero.

113.-Hospitales.

114.-Bibliotecas.

115.-Parques, Jardines, etc.

116. - Varios.

12.-Alcantarillado.

13.-Obras públicas municipales:

131. - Parte financiada con fondos generales.

132. - Idem íd. por los propietarios afectados mediante contribuciones especiales.

14.-Escuelas :

141.-Elementales.

142.--Secundarias.

143.-Técnicas y Vocacionales.

144

15.-Empresas y Servicios municipalizados :

151.-Servicio Municipal de Aguas.

152.- -Idem id. de Electricidad.

153.-Idem id. de Gas:

154.-Empresa Municipal de Tranvías.

155.-Idem íd. de Autobuses.

156.-Servicio Municipal de Telétonos. 
157.- Idem íd. de Calefacción.

158.- "Ferries".

159.-Otros Servicios Municipales:

1.591.-Aeropuerto.

1.592. - ...........

1.593. - ...........

160.- -Viviendas.

161.-Cementerios.

162.

2. Débitos a otros Municipios por empréstitos (estado complementarios número 4 (b).

3. Otras deudas a largo plazo.

4. Préstamos a corto plazo.

5. Cuentas acreedoras.

51.-Diversas.

52.-Débitos a otras Entidades locales (excepto por empréstitos).

53.-

6. Débitos a otros fondos municipales.

61

62

7. Descuento emisión obligaciones (pendientes de aplicación).

8. Otro Pasivo.

9. Reservas.

10. Inversión Patrimonial neta.

Pasivo contingente (se detalla en el estado financiero núm. III).

A continuación haremos un somero estudio del contenido, misión y f'ncionamiento contable de aquellas partidas del precedente estado financier's que pueden ofrecer mayor interés.

Activo fijo general.-Esta cuenta, o mejor dicho grupo de cuentas de naturaleza anúloga encuadradas bajo dicho título, tiene por objeto reflejar la situación contable de los diversos elementos dei inmovilizado municipal, tales como terrenos, edificios, equipo (mo biliario de oficinas, maquinaria y material de obras públicas y bie- 
nes muebles en general), parques, caminos, calles, aceras, puentes, metropolitano, viaductos, canales, obras portuarias, alcantarillado, etcétera.

Todos estos bienes, con excepción del llamado "equipo", sea cual fuera la forma de adquisición y la fuente de que procedan los recursos utilizados para la misma (emisión de empréstitos, créditos consignados en presupuestos ordinarios, subsidios, subvenciones, auxilios o donativos), deberán figurar en cuentas por su costo o valor estimado original en aquellos casos en que por proceder de donativos $\mathbf{u}$ otras fuentes semejantes-incluso el patrimonio primitivo-no exista un costo real para el Municipio, incrementados dichos valores originales por el de las reformas o mejoras de que hubieran sido objeto.

No se recomienda la práctica contable de hacer figurar en cuentas la amortización que corresponda a la depreciación estimada de los bienes del inmovilizado, los cuales, como ya hemos señalado, deben permanecer en cuenta por su valor de origen-real o calculado-mientras existan; su cesión o destrucción determinará su baja en el activo por el mismo valor. Correlativamente, la amortización o cancelación de la deuda municipal emitida para financiar los correspondientes presupuestos extraordinarios se cargará directamente a la cuenta de capital del Fondo (Inversión Patrimonial neta).

Estas reglas, sin embargo, no son de aplicación más que a los bienes fijos del activo general del Municipio, pero no a los afectos a empresas o servicios municipalizados, cuya contabilidad ha de ajustarse a las normas contables mercantiles, amortizándose periódicamente el inmovilizado.

Por lo que se refiere a los bienes muebles, serán valorados en fin de cada ejercicio fiscal, llevando las minusvalías, en su caso, a la cuenta de capital.

Resta decir únicamente que esta contabilidad se refiere sólo a los bienes generales del Municipio, quedando excluídos, por tanto, el inmovilizado de escuelas, empresas y servicios municipales, entidades todas que gozan de amplia autonomía contable.

La clasificación de los diversos bienes de activo fijo figura en un estado complementario ("schedule) núm. 1 del Manual), en el que se clasifican, por columnas, en terrenos, edificios, planta y equipo y otros bienes $y$, marginalmente, se adopta una clasifica- 
ción funcional de los mismos: administración general, protección a personas y bienes, obras públicas municipales, higiene y salubridad pública, sanidad municipal, beneficencia, servicios culturales y recreativos, etc.

Débitos de Escueias y de Empresas y Servicios Municipales.Cantidades adeudadas por estas entidades al Municipio por virtud de emisiones de empréstitos por cuenta de las mismas, teniendo en cuenta que si bien las empresas y servicios municipales-y aun las propias Escuelas, en ocasiones-no son entidades distintas del propio Municipio, sino meros servicios locales; sin embargo, constituyen entidades contables independientes, en virtud de su propia autonomía fiñanciera, teniendo, por tanto, para la contabilidad del Fondo Patrimonial, la cualidad de terceros.

Débrtos de otros Municipios por empréstitos. - Cantidades adeudadas por otras entidades municipales que han asumido, por causas diversas, la obligación de hacer frente al reembolso de cierta parte de la "deuda municipal». Dichas causas pueden ser: la anexión de parte del territorio municipal por otros Municipios, la ejecución de obras que, por afectar en parte a otras entidades locales, se comprometan éstas a satisfacer cierta parte de los empréstitos o préstamos contraídos para financiar dichas obras, etc.

Esta cuenta es objeto de estudio en el estado complementario número $1(a)$, en el que se clasifican marginalmente las clases de deuda según sus fines, y por columnas, se hacen constar los siguientes datos: nombres de los Municipios; empréstitos de vencimiento único; ídem de vencimiento escalonado; total; reserva para amortización de empréstitos de vencimiento único y deuda neta asumida (diferencia entre total y la reserva de amortización).

Fondo de amortización de empréstitos de vencimiento único:Es una cuenta de enlace con la contabilidad del "Sinking Fund". Como es sabido, en la práctica financiera americana es más frecuente la emisión de empréstitos de vencimiento único ("sinking fund debentures"), que la de empréstitos de vencimiento escalonado ("serial debentures"). $\mathrm{Y}$ para que la entidad emisora pueda hacer frente, en su día, al enorme desembolso que supone la amortización de todas las obligaciones emitidas, se recurre a la formación, durante la vida del empréstito, de un Fondo de amortización periódicamente dotado, con arreglo a las cifras del correspondiente cuadro financiero. 
La contabilidad de este Fondo-que estudiaremos en un próximo artículo-es independiente de la patrimonial en sí, siendo la función contable de la partida que estudiamos reflejar las cantidades que el "Sinking Fund" adeuda al Fondo Patrimonial como consecuencia de las dotaciones (anualidades de amortización) que recibe el primero, ya procedan directamente del presupuesto ordinario municipal, o, a través del mismo, de otras entidades (Escuelas, Empresas y Servicios Municipales u otros Municipios).

Otras partidas del activo.-Algunas, como Obras en curso, Tesorería, Cuentas deudoras y Otro activo real, no requieren explicación alguna.

En cuanto a la rúbrica "Débitos de otros fondos municipales" -común, por otra parte, a las demás contabilidades del Municipio-tiene por objeto recoger las cantidades adeudadas por otros fondos contables municipales al patrimonial, por conceptos distintos de la emisión de empréstitos, tales como anticipos, préstamos temporales, utilización de materiales, prestación de servicios, etc.

Las primas de emisión de empréstitos (emisión bajo la par) figurarán en el activo mientras no sean.amortizadas, por regla general, al mismo ritmo que los correspondientes títulos.

Por regla general, los empréstitos se destinan a financiar la adquisición, construcción, reforma o mejora de bienes, obras, instalaciones y servicios; es decir, los llamados gastos de primer establecimiento. Sin embargo, en ocasiones, y por diversas circunstancias, se utilizan para cubrir verdaderos gastos, que, aunque extraordinarios desde el punto de vista financiero, no constituyen inversión en bienes fijos; tales como auxilios para mitigar el paro, al Gobierno con fines patrióticos, catástrofes locales, etc., y aún, déficits de presupuestos ordinarios.

Todas estas partidas se contabilizan en la cuenta "Déficits y gastos extraordinarios capitalizados".

Empréstitos.-Refleja èl valor nominal de los títulos de la deuda municipal emitidos y en circulación, tanto los de carácter general como los emitidos por cuenta de Escuelas, Empresas y Servicios municipales. Asimismo se contabilizan bajo esta rúbrica los anticipos concedidos por el Gobierno del Dominio con arreglo a la "Municipal Improvments Act» de 1938, que tienen, a todos los efectos, el carácter de deuda consolidada. Se abona esta cuenta, o grupo de cuentas, del nominal puesto en circulación, con cargo 
a las correspondientes contrapartidas (Tesorería, Activo fijo general, Escuelas, etc.), y se adeuda de los títulos amortizados, siendo la contrapartida acreedora, según los casos, Capital, Déficits y Gastos extraordinarios capitalizados, Fondo de amortización de empréstitos, Débitos de Escuelas, por empréstitos, etc., teniendo en cuenta que el reembolso de los títulos amortizados, o la dotación al Fondo de amortización, corresponde, en todo caso, al Fondo de presupuesto ordinario, en cuya contabilidad se reflejarán todas las incidencias de dicho reembolso. El cargo a esta cuenta se practicará, por tanto, llegado el vencimiento de los títulos en circulación, incluso aquellos cuyo reembolso no fuera exigido por los tenedores o hubiera sido demorado por cualquier causa.

Otras partidas de pasivo.-Las restantes partidas que figuran en el pasivo del anterior estado de situación no precisan apenas ser aclaradas. Las números 2, 6 y 7 son de naturaleza análoga a la 5 , 9 y 11 del activo, respectivamente. Bajo el epígrafe "Reservas" se agrupan partidas reservadas con fines especiales, aunque de carácter patrimonial. Por último, la cuenta "Inversión Patrimonial neta) (Investment in Capital Assets) es la cuenta de capital de la contabilidad de este Fondo.

Contabilización. - A continuación exponemos una serie de asientos relativos a los principales hechos contables de este Fondo para su mejor interpretación :

1) Emisión de deuda municipal :

Tesoreria.

Prima de emisión de empréstitos (emisión bajo la par):

a Empréstitos.

a Descuento emisión empréstitos (emisión sobre la par).

2) Otras fuentes de ingresos extraordinarios que no supongan obligación de reembolso:

Tesoreria,

etc. a Inversión neta patrimonial.

3) Aplicación de los recursos :

a) Para atenciones municipales.

Obras en curso. 
Activo fijo general.

Déficits y gastos extraordinarios capitalizados.

a Tesoreria.

b) Si se trata de empréstitos emitidos por cuenta de Escuelas, etc.

Débitos de Escuelas, por empréstitos.

Débitos de Empresas y Servicios municipales, id. id.

a Tesorería.

4) Amortización de empréstitos de vencimientos escalonado:

Empréstitos :

a Inversión Patrimonial neta.

a Déficits y gastos extraordinarios capitalizados.

a Débitos de Escuelas, por empréstitos.

a Idem de Empresas y Servicios municipales, por empréstitos.

5) Amortización de empréstitos de vencimiento único:

a) Dotación al Fondo de amortización.

Fondo de amortización de empréstitos de vencimiento único.

a Inversión Patrimonial neta.

a Déficits y gaslos extraordinarios capitalizados.

a Débitos de Escuelas por.empréstitos.

a. Idem de Empresas y Servicios municipales por empréstitos.

b) Reembolso de los títulos, o, mejor dicho, vencimiento de los mismos :

Empréstitos.

a Fondo de amortización de empréstitos de vencimiento único.

José Trigo Daporta,

Profesor Mercantil Técnico de Hacienda 